\title{
Comparison of skin microvascular reactivity with hemostatic markers of endothelial dysfunction and damage in type 2 diabetes
}

\author{
Sandra Beer ${ }^{1,2}$ \\ François Feihl' \\ Juan Ruiz ${ }^{2}$ \\ Irène Juhan-Vague ${ }^{3}$ \\ Marie-Françoise Aillaud ${ }^{3}$ \\ Sandrine Golay Wetzel' \\ Lucas Liaudet ${ }^{4}$ \\ Rolf C Gaillard ${ }^{2}$ \\ Bernard Waeber' \\ Centre Hospitalier Universitaire \\ Vaudois, Division de Physiopathologie \\ Clinique,Lausanne, Suisse \\ 'Division de Physiopathologie \\ Clinique, Centre Hospitalier \\ Universitaire Vaudois et Université de \\ Lausanne, Lausanne, Suisse; ${ }^{2}$ Service \\ d'Endocrinologie, de Diabétologie et \\ de Métabolisme, Centre Hospitalier \\ Universitaire Vaudois et Université \\ de Lausanne, Lausanne, Suisse; \\ ${ }^{3}$ Laboratoire d'hématologie, Centre \\ Hospitalier Universitaire de Marseille; \\ Inserm UMR 626, Marseille, France; \\ ${ }^{4}$ Service de Médecine Intensive \\ de l'Adulte, Centre Hospitalier \\ Universitaire Vaudois et Université de \\ Lausanne, Lausanne, Suisse
}

Correspondence: Bernard Waeber CHUV, Division of Pathophysiology, MP I4/204, CH-I0I I Lausanne, Switzerland $\mathrm{Tel}+4 \mid$ II 3 I 40760

Fax $+4|2| 3 \mid 425$ I8

Email bernard.waeber@chuv.ch

\begin{abstract}
Aim: Patients with non-insulin-dependent diabetes mellitus (NIDDM) are at increased cardiovascular risk due to an accelerated atherosclerotic process. The present study aimed to compare skin microvascular function, pulse wave velocity (PWV), and a variety of hemostatic markers of endothelium injury [von Willebrand factor (vWF), plasminogen activator inhibitor-1 (PAI-1), tissue plasminogen activator (t-PA), tissue factor pathway inhibitor (TFPI), and the soluble form of thrombomodulin (s-TM)] in patients with NIDDM.

Methods: 54 patients with NIDDM and 38 sex- and age-matched controls were studied. 27 diabetics had no overt micro- and/or macrovascular complications, while the remainder had either or both. The forearm skin blood flow was assessed by laser-Doppler imaging, which allowed the measurement of the response to iontophoretically applied acetylcholine (endotheliumdependent vasodilation) and sodium nitroprusside (endothelium-independent vasodilation), as well as the reactive hyperemia triggered by the transient occlusion of the circulation.

Results: Both endothelial and non-endothelial reactivity were significantly blunted in diabetics, regardless of the presence or the absence of vascular complications. Plasma vWF, TFPI and s-TM levels were significantly increased compared with controls only in patients exhibiting vascular complications. Concentrations of t-PA and PAI-1 were significantly increased in the two groups of diabetics versus controls.

Conclusion: In NIDDM, both endothelium-dependent and -independent microvascular skin reactivity are impaired, whether or not underlying vascular complications exist. It also appears that microvascular endothelial dysfunction is not necessarily associated in NIDDM with increased circulating levels of hemostatic markers of endothelial damage known to reflect a hypercoagulable state.
\end{abstract}

Keywords: skin microcirculation, iontophoresis, pulse wave velocity, type 2 diabetes, hemostatic markers

\section{Introduction}

Endothelial cells have a strategic location at the interface between the blood and tissues and release a number of autocrine and paracrine substances critically involved in the regulation of vascular tone and the local control of flow and hemostasis (Verma and Anderson 2002). Insulin resistance and endothelial dysfunction are closely related during the development of type 2 diabetes (Caballero 2003; Kim et al 2006). In fact, endothelial dysfunction may be at the same time a cause and a consequence of the insulin resistance syndrome (Pinkney et al 1997; Wheatcroft et al 2003). Endothelial dysfunction and/or damage is associated with an increased cardiovascular risk and represents an early feature in the atherosclerotic process (Verma et al 2003; Brunner et al 2005).

The incidence of type 2 diabetes (non-insulin-dependent diabetes mellitus, NIDDM) is exploding worldwide and it is becoming a prominent burden on health 
care (Murray and Lopez 1996; Amos et al 1997). Patients with NIDDM incur a high risk of cardiovascular and renal complications (Nathan 1993). The present investigation was performed to assess whether there is a graded worsening in endothelial function and/or damage from non-diabetic subjects to patients with NIDDM, regardless of whether micro- and/or macrovascular complications are exhibited.

Endothelial function was evaluated using a laserDoppler flowmeter allowing the measurement of skin blood responses to iontophorized acetylcholine (Ach), which dilates by releasing nitric oxide (NO) from the endothelium, to sodium nitroprusside (SNP), which acts as a NO donor directly in vascular smooth muscle cells, and to local heating (Anderson 1999; Kubli et al 2000; Golay et al 2004). We also measured circulating levels of hemostatic regulatory molecules physiologically produced by endothelial cells, such as plasminogen activator-1 (PAI-1), von Willebrand factor (vWF), tissue plasminogen activator (tPA), free tissue factor pathway inhibitor (f-TFPI), and the soluble form of thrombomodulin (s-TM) (Cines et al 1998; Morange et al 2001, 2004). Increased plasma levels of these molecules may serve as markers of endothelial dysfunction and/or damage (Morange et al 2001; Blann et al 2002; Kato 2002; Kathiresan et al 2006). Finally, we determined pulse wave velocity as an index of arterial stiffness (Asmar et al 1995).

\section{Methods}

\section{Subjects}

We recruited 54 consecutive patients with type 2 diabetes referred to our outpatient clinic. The diagnosis of type 2 diabetes was based on the 1998 WHO criteria (Alberti and Zimmet 1998). Thirty-eight healthy subjects matched for gender and age served as controls. The latter had all a fasting glycemia $<6.1 \mathrm{mmol} / \mathrm{L}$, a body mass index $(\mathrm{BMI})<30 \mathrm{~kg} / \mathrm{m}^{2}$ and a blood pressure $<140 / 90 \mathrm{mmHg}$. They had no past history of heart, lung, kidney, endocrine, or liver disease and were not taking any medication. The protocol was approved by the Ethics Committee at our institution, and carried out in accordance with the principles of the Declaration of Helsinki as revised in 2000. Informed written consent was obtained from all subjects.

Our diabetic patients were routinely screened for macro- and microangiopathy (history of coronary heart disease, stroke or claudication, examination of carotid and peripheral arteries, and eye funduscopy by an ophthalmologist). In presence of 2 or more risk factors in addition to diabetes, a myocardial radionuclide scintigraphy or a stress echocardiography was performed (Consensus Development
Conference on Insulin Resistance 1998). This was followed by a coronarography if required. Coronary heart disease was considered present if any one of the following criteria was met: history of transmural myocardial infarction, history of coronary angioplasty, history of coronary bypass surgery, positive evidence for coronary artery disease on an exercise tolerance test, a stress echocardiogram, a myocardial scintigraphy, or a coronary angiogram. Ultrasonic examinations of carotid and peripheral arteries were obtained where appropriate. Diabetic nephropathy was defined as an albumin/creatinine ratio $>2 \mathrm{mg} / \mathrm{mmol}$ in a morning urine spot (Gerstein et al 2001; Jermendy et al 2001). Plasma levels of brain natriuretic peptide have been measured in the same population of diabetics and controls, and the results previously published (Beer et al 2005).

\section{Protocol}

All participants were studied on 2 mornings, after an overnight fast. The interval between the two sessions ranged from 1 to 14 days. On each study day the participants were asked to report at our research facility at 07.30 , and were left to rest on a bed. They were not allowed to drink beverages containing caffeine, xanthine, or alcohol and were asked to abstain from smoking. The investigations were carried out in a quiet room with air conditioning. Ambient temperature was systematically measured.

Session 1: After a 30-minute resting period a venous cannula was inserted into an antecubital vein for blood sampling. This was done without the use of a tourniquet to avoid the activation of the coagulation cascade. A $10-\mathrm{mL}$ blood sample was first collected in a prechilled sodium citratecoated tube for determining circulating levels of PAI-1, vWF, tPA, f-TFPI, and s-TM. After centrifugation at $4^{\circ} \mathrm{C}$, the plasma was stored at $-80^{\circ} \mathrm{C}$. An additional $10-\mathrm{mL}$ blood sample was drawn in an heparinized tube for measurement of plasma, creatinine, total cholesterol, HDL-cholesterol, LDL-cholesterol, and triglyceride concentrations.

Session 2: The outline of the study protocol is illustrated in Figure 1. On arrival a venous cannula was inserted in an antecubital vein and a $10-\mathrm{mL}$ blood sample collected in a heparinized tube for measurement of plasma glucose, and insulin concentrations. Forearm skin temperature was assessed using a cutaneous probe (G. Mettraux, Crissier, Switzerland). Blood pressure and heart rate were measured in supine position using an automated oscillometric device (Datascope Accutor 1A, MS Cardio-Medical, Brunnen, Switzerland). At 08:00 the participants received a standard breakfast containing $75 \mathrm{~g}$ carbohydrates and $40 \mathrm{~g}$ 


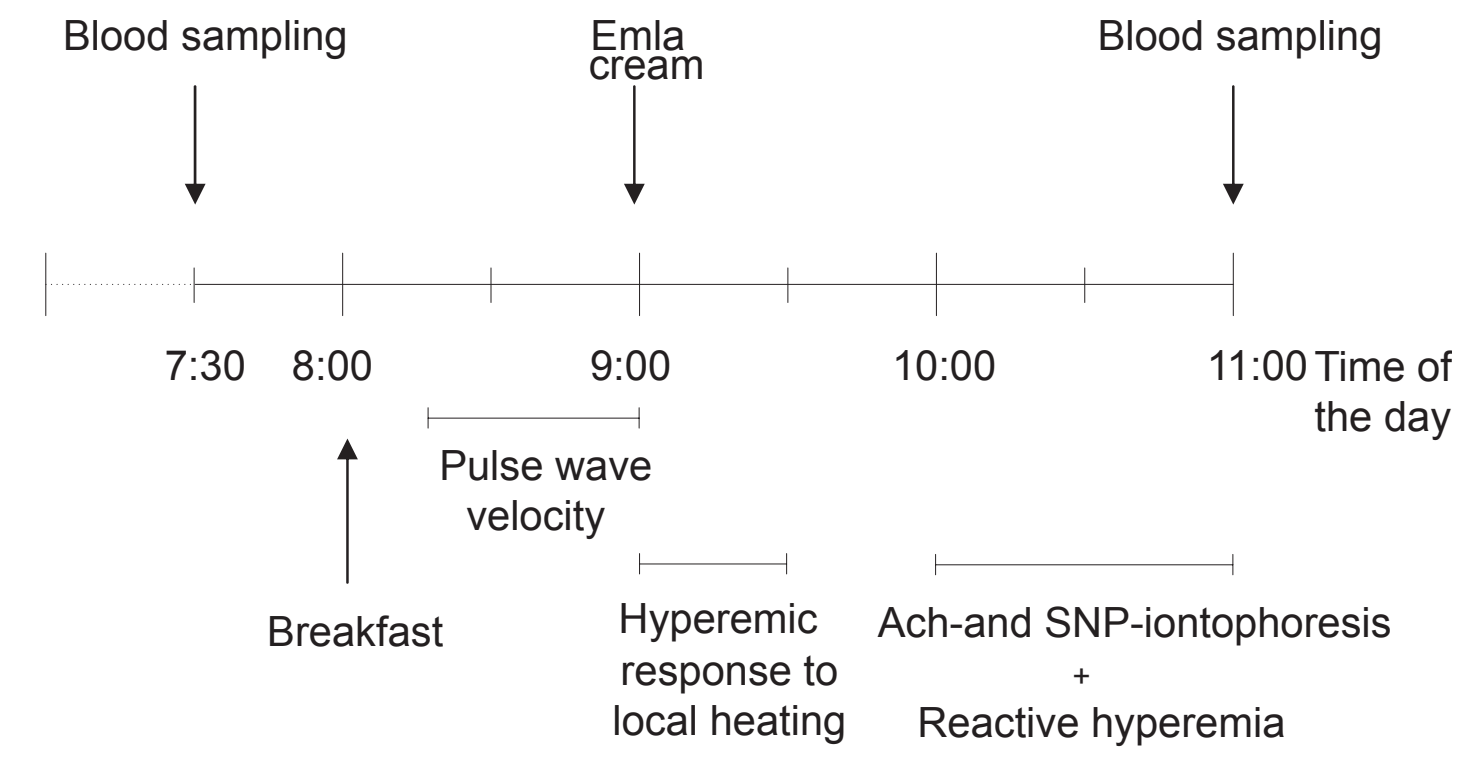

Figure I Outline of the study protocol.

Abbreviations: Ach, acetylcholine; SNP, sodium nitroprusside.

fat. Pulse wave velocity was determined between $08: 15$ and 09:00. The hyperemic responses to local heating of the forearm skin were then assessed, between 09:00 and 09:30. This was followed, between 10:00 to 11:00, by the measurement of the cutaneous microvascular responses to iontophorized (Ach and SNP), as well as to the transient interruption of forearm circulation (reactive hyperemia, $\mathrm{RH})$. Blood sampling $(10 \mathrm{~mL})$ was repeated at the end of the session for determination of plasma glucose and insulin concentrations.

\section{Measurement of pulse wave velocity (PWV)}

The transmission velocity of the pulse pressure wave between the right carotid on one hand and the right femoral and radial arteries on the other hand was assessed using a validated, automatic device (Complior Artech Medicla) (Asmar et al 1995). The distance between the recording sites was determined with a tape-measure over the surface of the body. PWV was expressed in meters/sec.

\section{Measurement of skin blood flow}

A laser-Doppler imager (Moor Instruments, Axminister, UK) was used to measure skin blood flow, as described previously (Kubli et al 2000). This device allows the scanning of a region of interest, with no skin contact. The distance traveled by the incident laser beam from the laser aperture to the skin was set at $41 \mathrm{~cm}$. The total flow is expressed in perfusion units (PU) according to the principle of laser-Doppler flowmetry.
The sites chosen for the measurements were located on the proximal anterior face of the right forearm and were selected so as to exclude visible veins.

\section{Response of skin blood flow to local heating}

Two stainless steel, temperature-controlled, ring-shaped chambers with inner diameter, outer diameter, and thickness of 8,25 , and $8 \mathrm{~mm}$, respectively, were affixed to the forearm skin with double-sided tape, filled to the rim with deonized water and overlaid with a transparent glass coverslip (Golay et al 2004). The skin underneath the coverslip and water was thus accessible to laser Doppler imaging, was programmed to repetitively scan the area comprising both chambers every 30 seconds.

The chambers were connected to analog temperature controllers with adjustable set-point. Their temperature was set at $34^{\circ} \mathrm{C}$ until a stable blood flow reading was obtained, then raised in 60 seconds to $37^{\circ} \mathrm{C}$ in one chamber and $41^{\circ} \mathrm{C}$ in the other, then maintained at this level for the next 11 minutes.

\section{Response to iontophoretically applied Ach and SNP} Iontophoresis is a method of noninvasive transfer of charged molecules through the skin by means of an externally applied electrical current. To follow with laser Doppler flowmetry, the responses of skin blood flow to iontophoretically applied Ach and SNP, we constructed a ring-shaped chamber (10 $\mathrm{mm}$ internal diameter) in black neoprene fitted on the inside with an annular copper electrode connected to an iontophoresis controller (MIC1-e; Moor Instruments, Axminster, United Kingdom). The chamber was affixed to the skin with double-sided tape and filled to 
the rim with a solution of either $1 \%$ Ach or $0.1 \%$ SNP in deionized water. The drug solutions were prepared fresh on each day (Ach, Sigma Chemie, Buchs, Switzerland; SNP, Schwarz Pharma, Aubonne, Switzerland). To avoid artifacts generated at the air - liquid interface, the chamber was covered with a thin, clear glass lid, with care taken to avoid trapping any bubbles underneath. The iontophoresis controller was also connected to an indifferent electrocardiograph electrode placed on the wrist. Polarity was adapted to the electric charge of the vasoactive molecule (chamber positive for Ach and negative for SNP). For testing Ach, 3 different doses of current charge density (1.4, 7 , and $28 \mathrm{mC} / \mathrm{cm}^{2}$ ) were administered, each in a pulsed fashion over 7 minutes, with 2 minutes interposed between each dose. For SNP, the current charge density was 38 $\mathrm{mC}$ (Kubli et al 2000). The skin was pretreated with an anesthetic cream (Emla cream 5\%, Astra Pharmaceutica AG, Dietikon, Switzerland) applied for 1 hour under an occlusive dressing (Tegaderm, 3M Health Care Ltd, UK), in order to prevent current-induced, axon reflex-mediated vasodilation (Wardell et al 1993; Berghoff et al 2002).

\section{Reactive hyperemia}

Reactive hyperemia (RH) was assessed with the laser-Doppler imager in the forearm skin, at a site not exposed to local anesthesia. The arterial occlusion was achieved by a pressure cuff placed on the arm and inflated at a suprasystolic pressure (220 mmHg) for 3 minutes.

\section{Laboratory tests}

The plasma levels of vWF, PAI-1, tPA, f-TFPI, and s-TM were measured using commercially available enzyme-linked immunosorbent assays (Diagnostica Stago, Asnières, France).

\section{Statistical analysis}

Results are presented as means \pm SD. Three groups of subjects (controls, diabetics without any vascular complication, and diabetics with microvascular and/or macrovascular complications) were compared with simple parametric analysis of variance. Where justified by very asymmetric distribution not amenable to logarithmic transform, a Kruskall-Wallis test was used instead. When the F (or chi-square) value was significant, pairwise comparisons were carried out with Dunn's test or its nonparametric adaptation (Glanz 1992). The alpha level of all tests was set at 0.05 . All computations were performed with the JMP software, version 3.2.2 (SAS Institute, Cary, NC, USA).

\section{Results \\ Characteristics of the study population}

The baseline characteristics of the study subjects are summarized in Table 1. Diabetic patients were divided into 2 subgroups according to the presence $(n=27)$ or the absence of micro- and/or macrovascular complications $(n=27)$. Among the former patients, 9 exhibited microvascular complications and 5 macrovascular complications only, whereas 13 patients had both types of complications. Body mass index (BMI) as well as systolic and diastolic blood pressures were significantly higher in the two groups of diabetics than in the controls. Significant differences in mean levels of $\mathrm{Hb} 1 \mathrm{Ac}$, fasting and post-prandial plasma glucose, fasting plasma insulin, plasma creatinine, and urinary albumin/creatinine ratio were observed between the two groups of diabetics. An exercise tolerance test, a coronary angiogram, a stress echocardiogram, and a myocardial radionuclide scintigraphy were performed in $6,5,24$, and 11 patients, respectively. All patients who underwent the echocardiographical examination showed an ejection fraction above $50 \%$.

Table 2 shows the various treatments received at the time of examination. Blockers of the renin-angiotensin system, $\beta$-blockers, and anti-aggregatory agents were taken significantly more often in patients with than in those without vascular complications.

There was no significant difference in room and skin temperature between the 3 study groups (Table 3 ).

\section{Measurement of pulse wave velocity (Table 3)}

Carotid to radial PWV was comparable in the control subjects and in the two groups of diabetics. Diabetic patients with vascular complications showed significantly increased values for carotid to femoral PWV compared with both control subjects and diabetic patients without vascular complications.

\section{Measurement of skin blood flow (Table 3)}

No significant difference in baseline skin blood flow was observed between the control subjects and the two groups of diabetics regardless of whether the skin had been exposed to the anesthetic cream.

\section{Response of skin blood flow to local heating (Table 3)}

The maximal skin microvascular dilation induced by increasing the local temperature to $37^{\circ} \mathrm{C}$ was of similar 
Table I Characteristics of study participants

\begin{tabular}{|c|c|c|c|}
\hline & \multirow[t]{2}{*}{ Controls } & \multicolumn{2}{|l|}{ Diabetics } \\
\hline & & $\begin{array}{l}\text { without vascular } \\
\text { complications }\end{array}$ & $\begin{array}{l}\text { with vascular } \\
\text { complications }\end{array}$ \\
\hline Number of subjects & 38 & 27 & 27 \\
\hline Duration of diabetes (years) & - & $6.4 \pm 6.2$ & $10.8 \pm 7.8$ \\
\hline Age (years) & $56.0 \pm 11.1$ & $54.4 \pm 7.7$ & $57.9 \pm 7.0$ \\
\hline $\operatorname{Sex}(M / F)$ & $25 / 13$ & $16 / 11$ & $22 / 5$ \\
\hline Body mass index $\left(\mathrm{kg} / \mathrm{m}^{2}\right)$ & $23.0 \pm 2.5$ & $30.4 \pm 4.8^{\mathrm{b}}$ & $31.4 \pm 5.4^{b}$ \\
\hline Waist to hip ratio & $0.92 \pm 0.07$ & $1.01 \pm 0.05^{\mathrm{b}}$ & $1.04 \pm 0.08^{b}$ \\
\hline Blood pressure, systolic (mmHg) & $117 \pm 10$ & $133 \pm 17^{b}$ & $142 \pm 16^{b}$ \\
\hline Blood pressure, diastolic $(\mathrm{mmHg})$ & $68 \pm 8$ & $78 \pm 11^{b}$ & $82 \pm 9 b$ \\
\hline Smoking (pack-years) & $1.7 \pm 7.2$ & $9.7 \pm 23.0^{\mathrm{a}}$ & $8.5 \pm 13.5^{\mathrm{a}}$ \\
\hline Plasma glucose, fasting (mM) & $4.8 \pm 0.5$ & $7.0 \pm 1.6^{b}$ & $8.4 \pm 2.2^{\mathrm{bc}}$ \\
\hline Plasma glucose, post-prandial (mM) & $5.1 \pm 0.9$ & $12.4 \pm 2.4^{b}$ & $14.2 \pm 2.6^{\mathrm{bc}}$ \\
\hline \multicolumn{4}{|l|}{ Plasma insulin (mU/L) } \\
\hline fasting & $10.9 \pm 5.3$ & $23.5 \pm 13.2^{b}$ & $35.4 \pm 21.7^{\mathrm{bc}}$ \\
\hline post-prandial & $40.5 \pm 23.6$ & $79.4 \pm 50.7^{b}$ & $82.2 \pm 48.8^{b}$ \\
\hline HOMA-IR index & $2.3 \pm 1.3$ & $7.5 \pm 5.2^{b}$ & $13.5 \pm 9.7^{b c}$ \\
\hline HbAlc (\%) & NA & $7.3 \pm 1.1$ & $8.2 \pm 1.3^{c}$ \\
\hline HDL-cholesterol (mM) & $1.62 \pm 0.34$ & $1.29 \pm 0.36^{\mathrm{b}}$ & $1.30 \pm 0.30^{\mathrm{b}}$ \\
\hline LDL-cholesterol (mM) & $2.96 \pm 0.89$ & $2.85 \pm 0.71$ & $2.75 \pm 0.87$ \\
\hline Triglycerides (mM) & $0.94 \pm 0.47$ & $1.87 \pm 0.80^{\mathrm{b}}$ & $2.09 \pm 1.92^{b}$ \\
\hline Plasma creatinine $(\mu \mathrm{M})$ & $89 \pm 10$ & $87 \pm 15$ & $104 \pm 26^{\mathrm{bc}}$ \\
\hline Urine albumin/creatinine ratio ${ }^{a}$ & $0.6 \pm 0.5$ & $0.8 \pm 0.6$ & $32.4 \pm 83.9^{\mathrm{bc}}$ \\
\hline
\end{tabular}

Notes: Means \pm SD. NA, not available.

Statistical analysis: one way parametric ANOVA except for smoking (Kruskall-Wallis non parametric ANOVA).

${ }^{\mathrm{a}} \mathrm{p}<0.05$ vs controls; ${ }^{\mathrm{b}} \mathrm{p}<0.01$ vs controls; ${ }^{\mathrm{c}} \mathrm{p}<0.0$ I diabetics with vs diabetics without vascular complications.

magnitude in the three study groups. However, when the skin temperature was increased to $41^{\circ} \mathrm{C}$, maximal vasodilation was significantly lower in diabetics than in controls. The two diabetic groups did not differ in this respect.

\section{Response to iontophoretically applied Ach and SNP (Table 3)}

Three different doses of current charge density were tested for the iontophoresis of Ach. The peak vasodilatory responses to the $1.4 \mathrm{mC} / \mathrm{cm}^{2}$ and $7 \mathrm{mC} / \mathrm{cm}^{2}$ charges were comparable in the thee groups. With the highest $28 \mathrm{mC} / \mathrm{cm}^{2}$ charge, however, a significant attenuation of the responses was observed in the two groups of diabetics compared with controls. The responses were equally blunted in the diabetics with and without vascular complications. The peak responses to iontophorized SNP were significantly attenuated in the two groups of diabetes, with no difference, however in the presence and the absence of vascular complications.

\section{Reactive hyperemia (Table 3)}

The peak hyperemic response was significantly lower in diabetics than in controls, to a similar extent in patients with and without vascular complications.

\section{Laboratory tests (Table 4)}

In diabetics without complications, the plasma levels of PAI-1 and t-PA were elevated to the same extent as in those with complications, whereas the levels of the three other markers were normal. In diabetic patients with vascular complications, the plasma concentrations of all hemostatic endothelial cell markers were significantly increased compared with control subjects.

\section{Discussion}

Type 2 diabetes mellitus is becoming increasingly prevalent in both developing and industrialized countries, representing therefore a leading cause of health disability and health care cost (Murray and Lopez 1996; Amos et al 1997). NIDDM is 
Table 2 Number of patients (\%) on various therapies

\begin{tabular}{llll}
\hline & $\begin{array}{l}\text { Diabetics without } \\
\text { vascular complications }\end{array}$ & $\begin{array}{l}\text { Diabetics with } \\
\text { vascular complications }\end{array}$ \\
\hline Insulin & $13(48 \%)$ & $19(70 \%)$ & $\mathrm{NS}^{\mathrm{a}}$ \\
Oral antidiabetics & $19(70 \%)$ & $15(56 \%)$ & $\mathrm{NS}$ \\
ACE-I or AT,-receptor blocker & $14(52 \%)$ & $21(78 \%)$ & $<0.05$ \\
$\beta$-blocker & 0 & $12(44 \%)$ & $\mathrm{NS}$ \\
Diuretic & $8(30 \%)$ & $13(48 \%)$ & $\mathrm{NS}$ \\
Calcium antagonist & $7(26 \%)$ & $9(33 \%)$ & $\mathrm{NS}$ \\
Statin & $10(37 \%)$ & $16(59 \%)$ & $<0.00 \mathrm{I}$ \\
Anti-aggregatory agents & $9(33 \%)$ & $24(89 \%)$ & \\
\hline
\end{tabular}

${ }^{a}$ not significant

Abbreviation: ACE-I, angiotensin converting enzyme inhibitor.

a strong risk factor not only for nephropathy and end stage renal failure, but also for all manifestations of atherosclerotic disease (Nathan 1993). Most patients with NIDDM die from cardiovascular complications (Laasko and Lehto 1997), which can be explained by the fact that NIDDM is frequently associated with other risk factors such as hypertension, central obesity, hyperinsulinemia, and dyslipidemia, the last named being characterized mainly by elevated serum total triglycerides and low HDL cholesterol, ie, components of the metabolic syndrome (Reaven et al 1996; Pyorala et al 2000; Waeber et al 2001). Not surprisingly most of our patients treated for NIDDM received also medications for high blood pressure and dyslipidemia (Table 2). Of note also is the fact that our patients, whether or not they had detectable vascular complications, had increased waist to hip ratio, plasma insulin, glucose and triglyceride levels, and decreased plasma HDL cholesterol levels compared with age- and sex-matched healthy controls (Table 1). The patients with

Table 3 Pulse wave velocity and microvascular skin blood flow responses in diabetic patients with and without vascular complications compared with control subjects (means \pm SD)

\begin{tabular}{|c|c|c|c|}
\hline & \multirow{2}{*}{$\frac{\text { Controls }}{(n=38)}$} & \multicolumn{2}{|l|}{ Diabetics } \\
\hline & & without complications $(n=27)$ & with complications $(n=27)$ \\
\hline Room temperature $\left({ }^{\circ} \mathrm{C}\right)$ & $24.0 \pm 0.8$ & $24.3 \pm 1.1$ & $24.1 \pm 0.7$ \\
\hline Skin temperature $\left({ }^{\circ} \mathrm{C}\right)$ & $32.7 \pm 1.1$ & $32.4 \pm 1.2$ & $32.8 \pm 1.0$ \\
\hline \multicolumn{4}{|l|}{ Baseline skin blood flow (PU) } \\
\hline anesthetized skin & $60 \pm 13$ & $60 \pm 10$ & $63 \pm 13$ \\
\hline unanesthetized skin & $89 \pm 28$ & $74 \pm 20$ & $89 \pm 30$ \\
\hline \multicolumn{4}{|l|}{ Pulse wave velocity $(\mathrm{m} / \mathrm{sec})$} \\
\hline carotid-femoral artery & $9.4 \pm 2.2$ & $9.9 \pm 1.8$ & $11.8 \pm 2.2^{b, c}$ \\
\hline carotid-radial artery & $10.2 \pm 1.9$ & $9.8 \pm 1.7$ & $10.0 \pm 0.9$ \\
\hline \multicolumn{4}{|l|}{$\begin{array}{l}\text { Maximal response to local } \\
\text { heating (PU) }\end{array}$} \\
\hline $37^{\circ} \mathrm{C}$ & $52 \pm 45$ & $54 \pm 41$ & $56 \pm 40$ \\
\hline $41^{\circ} \mathrm{C}$ & $322 \pm 130$ & $257 \pm 1 I^{a}$ & $242 \pm 112^{\mathrm{a}}$ \\
\hline \multicolumn{4}{|l|}{ Maximal response to Ach (PU) } \\
\hline $1.4 \mathrm{mC} / \mathrm{cm}^{2}$ & $229 \pm 119$ & $211 \pm 139$ & $163 \pm 94$ \\
\hline $7.0 \mathrm{mC} / \mathrm{cm}^{2}$ & $362 \pm 89$ & $317 \pm 115$ & $301 \pm 115$ \\
\hline $28.0 \mathrm{mC} / \mathrm{cm}^{2}$ & $395 \pm 94$ & $345 \pm 99 a$ & $337 \pm 102^{\mathrm{a}}$ \\
\hline Maximal response to SNP (PU) & $326 \pm 80$ & $274 \pm 86^{b}$ & $255 \pm 65^{b}$ \\
\hline Maximal RH (PU) & $183 \pm 67$ & $136 \pm 55^{a}$ & $134 \pm 69^{a}$ \\
\hline
\end{tabular}

Analysis with one way parametric ANOVA

${ }^{a} \mathrm{p}<0.05$ vs controls; ${ }^{\mathrm{b}} \mathrm{p}<0.0$ I vs controls; ${ }^{\mathrm{p}}<0.0$ I vs diabetics without complications.

Abbreviations: Ach, acetylcholine; $\mathrm{PU}$, perfusion units; $\mathrm{RH}$, reactive hyperemia; SNP, sodium nitroprusside. 
Table 4 Plasma concentrations of hemostatic endothelial cell markers in diabetic patients with and without vascular complications compared with control subjects (means \pm SD)

\begin{tabular}{llll}
\hline & \multicolumn{1}{c}{ Controls } & Diabetics & with complications $\mathbf{n}=\mathbf{2 7})$ \\
\cline { 2 - 4 } & $(\mathbf{n}=\mathbf{3 8})$ & without complications $\mathbf{n}=\mathbf{2 7})$ & $50.0 \pm 40.4^{\mathrm{b}}$ \\
\cline { 2 - 4 } PAI-I $(\mathrm{ng} / \mathrm{mL})$ & $13.7 \pm 7.5$ & $51.1 \pm 37^{\mathrm{b}}$ & $10.5 \pm 4.4^{\mathrm{b}}$ \\
tPA $(\mathrm{ng} / \mathrm{mL})$ & $6.2 \pm 4.1$ & $10.9 \pm 4.4^{\mathrm{b}}$ & $180 \pm 65^{\mathrm{bc}}$ \\
VWF (IU/dL) & $136 \pm 48$ & $145 \pm 50$ & $9.6 \pm 2.5^{\mathrm{ac}}$ \\
f-TFPI $(\mathrm{ng} / \mathrm{mL})$ & $7.6 \pm 3.9$ & $7.8 \pm 2.5$ & $77.1 \pm 46.7^{\mathrm{ac}}$ \\
s-TM $(\mathrm{ng} / \mathrm{mL})$ & $56.8 \pm 30.5$ & $53.4 \pm 16$ & \\
\hline
\end{tabular}

Statistical analysis: one way parametric ANOVA except for PAI-I (Kruskall Wallis non parametric ANOVA)

${ }^{\mathrm{a}} \mathrm{p}<0.05$ vs controls; ${ }^{\mathrm{b}} \mathrm{p}<0.01$ vs controls; ${ }^{\mathrm{c}} \mathrm{p}<0.05$ vs diabetics without complications.

Abbreviations: PAI-I, plasminogen activator inhibitor-I; vWF, von Willebrand factor; tPA, tissue plasminogen activator; f-TFPI, free tissue pathway factor inhibitor; s-TM, soluble form of thrombomodulin.

vascular complications showed significantly higher plasma glucose, insulin, and $\mathrm{HbA} 1 \mathrm{c}$ levels, as well as significantly higher systolic blood pressure than patients without vascular complications. These differences were seen despite a very similar pattern of drug prescriptions in the two groups, except a substantially greater proportion of patients on antiplatelet therapy among individuals with vascular complications (Table 2). The poorer glucose and blood pressure control achieved might have accelerated the atherosclerotic vascular disease observed in the latter patients. Whether the presence of vascular complications made our patients with NIDDM less responsive to antihypertensive therapy is another possibility to be considered.

Impaired endothelial function, as reflected by a decreased endothelium-dependent vasodilation, is a hallmark of vascular disease states (Brunner et al 2005). A common denominator to all cardiovascular risk factors is an increased oxidative stress, resulting in the scavenging of NO, the potent relaxing factor released by the endothelium (Waeber and Feihl 2005; Feletou and Vanhoutte 2006. This has been repeatedly documented in patients with NIDDM (Calles-Escandon and Cipolla 2001; Ding and Triggle 2005). Endothelial dysfunction refers usually to a blunted vasodilatory response to Ach, which releases NO from the endothelium, while the vasorelaxant activity of SNP or nitroglycerin, which act as NO donors in vascular muscle cells, is maintained (Deanfield et al 2005). Another way of testing endothelial function is to assess the flow-mediated vasodilation, ie, the vasodilation occurring after transient occlusion of the circulation (Anderson 1999; Deanfield et al 2005). Still another means to evaluate endothelium function in humans is to study the vasodilation induced by local skin heating (Kellogg et al 1999).

Both the endothelium-dependent and -independent blood flow responses (measured using venous occlusion plethysmography or ultrasonography) have been reported to be attenuated in the forearm circulation of patients with NIDDM (Zenere et al 1995; Williams et al 1996; Hogikyan et al 1998; Natali et al 2006). In three of these studies, hypertensive and dyslipidemic patients were excluded (Zenere et al 1995; Williams et al 1996; Hogikyan et al 1998), whereas in the fourth, $40 \%$ and $10 \%$ of patients had hypertension (either treated or untreated) or dyslipidemia (treated with a fibrate), respectively (Natali et al 2006). Notably, in Williams et al (1996) study, measurements were performed after administration of aspirin to inhibit the endogenous production of vasoactive prostanoids from the endothelium. Impaired vasodilatory responses to Ach and SNP have also been reported in the skin microvasculature of type 2 diabetics (Morris et al 1995; Lim et al 1999; Caballero et al 1999. Ach and SNP were applied transcutaneously by iontophoresis and skin blood flow changes measured by laser Doppler imaging. Patients receiving blood pressure- or lipid-lowering drugs were excluded. We made similar observations in the present investigation, as both the Ach and SNP responses were blunted in the presence of NIDDM. It has to be stressed that most of our patients were taking not only antidiabetic medications, but also blood pressure- and lipid-lowering agents, as well as anti-aggregatory drugs. The need for this polypharmacy in high risk patients with NIDDM has been well documented recently (American Diabetes Association 2001; Waeber et al 2001). An original aspect of our investigation deals therefore with the finding of a persistently impaired microvascular reactivity in type 2 diabetes despite efforts directed to control all traditional cardiovascular risk factors. Also, blockers of the renin-angiotensin system and statins were the treatments of choice in our patients, which corresponds to the current recommendations for the pharmacological management of hypertension and dyslipidemia in 
patients with NIDDM (American Diabetes Association 2001; Waeber et al 2001, 2003; European Society of Hypertension 2003). The lack of normalization of skin microvascular reactivity in our patients might have been expected since impaired responses to iontophoretically applied Ach and SNP have been reported in subjects with impaired glucose tolerance or increased fasting glucose, already before the development of established type 2 diabetes (Caballero et al 1999; Vehkavaara et al 1999).

In addition to the reduced vasodilatory response to iontophorized Ach and SNP, we observed a significant attenuation of the hyperemia caused by local heating of the skin. This is in agreement with the previous experience of other investigators (Vinik et al 2001). Of note is that the abnormal skin response to local heating may reflect not only endothelial dysfunction, but also the impaired reactivity to nociceptive stimulation and the alterations in neuronal release of vasoactive peptides encountered in type 2 diabetes (Stansberry et al 1999; Vinik et al 2001). Interestingly, the limited microvascular vasodilation triggered by raising the skin temperature had already been observed in patients at risk of developing NIDDM, as manifested by elevated plasma glucose concentrations still below the diabetic range (Jaap et al 1994, 1997).

The last method we used to explore the endothelial function of the skin forearm microcirculation was the measurement of the flow-mediated vasodilatory capacity, done by assessing the reactive hyperemia that occurs after the release of a transient interruption of the circulation in the brachial artery. A blunted response was evidenced in the diabetics, as expected from previous observations of brachial artery diameter changes during the post-ischemic period (Caballero et al 1999).

All methods we used for endothelial function testing showed an impaired reactivity of skin microcirculation. Our diabetic patients were subdivided in 2 groups according to the presence or absence of overt micro- and/or macrovascular complications. It was hypothesized that endothelial function would be altered to a greater degree in patients with manifest vascular damage. This was, however, not the case: there was no way to discriminate between patients with and without vascular complications based on any of the functional markers that were measured. By contrast, PWV, which is known to closely reflect arterial thickness (Laurent et al 2006), was on average higher in patients with than in those without vascular complications, while no difference was detected between the latter patients and control subjects. Increased arterial stiffness might occur before the onset of NIDDM (Henry et al 2003) and has an independent predictive value for mortality already at the stage of glucose intolerance (Cruickshank et al 2002). Among our diabetic patients, only those with clinical micro- and/or macrovascular disease exhibited higher PWV in comparison with control subjects. In theory, functional alterations of the endothelium should occur before structural changes of the arterial wall. Such a sequence in the atherosclerotic process could still be detected in our patients, even if they took a number of medications for controlling hyperglycemia, high blood pressure and/or dyslipidemia.

The endothelium is perturbed at all stages of atherogenesis: functional abnormalities are seen early during the course of the arterial wall disease, which is followed by a progressive injury of endothelial cells as a result of the underlying inflammatory process and the development of a prothrombotic state (Ross 1999; Libby and Simon 2001). The concept of "vulnerable blood" has been proposed to reflect the hypercoagulability associated with atherosclerosis and the predominant release of procoagulant factors occurring which characterizes this condition (Naghavi et al 2003). Increased circulating levels of vWF, PAI-1, t-PA, TFPI, and s-TM have been reported in patients with NIDDM (Collier et al 1992; McGill et al 1994; Bagg et al 2001; Aso et al 2002; Leurs et al 2002; Rigla et al 2006). In our study, plasma concentrations of all these markers of endothelial suffering were significantly higher in patients with vascular complications than in control subjects. In the absence of vascular complications, however, only plasma t-PA and PAI-1 levels were significantly increased compared with those in non-diabetic controls. Notably, the presence of vascular or renal complications has been found in relation to an increased propensity to develop coagulation and fibrinolysis abnormalities (Kario et al 1995; Yano et al 2003; Erem et al 2005). Our findings are relevant as they show that endothelial dysfunction in NIDDM is not necessarily accompanied by a clustering of hemostatic abnormalities, as would be expected if endothelial cells were damaged. The fact that most of our patients received medications known to have a protective action on the endothelium might have contributed to this situation.

As a final and practical note, the apparent progression seen in our data from normal plasma levels of vWF, f-TFPI and s-TM as well as a normal PWV in diabetics without vascular or renal complications, to generalized abnormalities of these parameters when such complications are detected, suggests that the serial measurement of some, or possibly all, of these parameters might be useful for the long term monitoring of these patients. Longitudinal studies would be required to verify this point. 
In summary, our data show that patients with NIDDM, when treated as required for coexisting risk factors, exhibit endothelial dysfunction at the level of the skin microvasculature. This functional abnormality is associated with increased levels of some, but not all, hemostatic markers of endothelial damage as long as there is no concurrent micro- and/or macrovascular complication. Further studies are however needed to assess whether the control of all cardiovascular risk factors allows the prevention and/or the regression of endothelial damage in patients with type 2 diabetes.

\section{Disclosures}

None of the authors have conflicts of interest to declare.

\section{Abbreviations}

Ach, acetylcholine; NIDDM, non-insulin-dependent diabetes mellitus; PAI-1, plasminogen activator inhibitor-1; PU, perfusion units; RH, reactive hyperemia; SNP, sodium nitroprusside; tPA, tissue plasminogen activator; vWF, von Willebrand factor; f-TFPI, free tissue pathway factor inhibitor; s-TM, soluble form of thrombomodulin.

\section{References}

Alberti KG, Zimmet PZ. 1998. Definition, diagnosis and classification of diabetes mellitus and its complications. Part 1: diagnosis and classification of diabetes mellitus provisional report of a WHO consultation. Diab Med, 15:539-53.

American Diabetes Association. 2001. Standards of medical care for patients with diabetes mellitus. Diabetes Care, 24 (Suppl 1):33-55.

Amos AF, McCarty DJ, Zimmet P. 1997. The rising global burden of diabetes and its complications: estimates and projections to the year 2010. Diab Med, 14:S1-85.

Anderson TJ. 1999. Assessment and treatment of endothelial dysfunction in humans. J Am Coll Cardiol, 34:631-8.

Asmar R, Benetos A, Topouchian J, et al. 1995. Assessment of arterial distensibility by automatic pulse wave velocity measurement. Validation and clinical application studies. Hypertension, 26:485-90.

Aso Y, Fujiwara Y, Tayama K, et al. 2002. Elevation of von Willebrand factor in plasma in diabetic patients with neuropathic foot ulceration. Diab Med, 19:19-26.

Bagg W, Ferri C, Desideri G, et al. 2001. The influences of obesity and glycemic control on endothelial activation in patients with type 2 diabetes. J Clin Endocrinol Metab, 86:541-7.

Beer S, Golay S, Bardy D, et al. 2005. Increased plasma levels of N-terminal brain natriuretic peptide (NT-proBNP) in type2 diabetic patients with vascular complications. Diab Metab, 31:567-73.

Berghoff M, Kathpal M, Kilo S, et al. 2002. Vascular and neural mechanisms of ACh-mediated vasodilation in the forearm cutaneous microcirculation. J Appl Physiol, 92:780-8.

Blann AD, McCollum CN, Lip GY. 2002. Relationship between plasma markers of endothelial cell integrity and the Framingham cardiovascular disease risk-factor scores in apparently healthy individuals. Blood Coagul Fibrinolysis, 13:513-8.

Brunner H, Cockcroft JR, Deanfield J, et al. 2005. Endothelial function and dysfunction. Part II: Association with cardiovascular risk factors and diseases. A statement by the Working Group on Endothelins and Endothelial Factors of the European Society of Hypertension. J Hypertens, 23:233-46.
Caballero AE, Arora S, Saouaf R, et al. 1999. Microvascular and macrovascular reactivity is reduced in subjects at risk for type 2 diabetes. Diabetes, 48:1856-62.

Caballero AE. 2003. Endothelial dysfunction in obesity and insulin resistance: a road to diabetes and heart disease. Obes Res, 11:1278-89.

Calles-Escandon J, Cipolla M. 2001. Diabetes and endothelial dysfunction: a clinical perspective. Endocr Rev, 22:36-52.

Cines DB, Pollak ES, Buck CA, et al. 1998. Endothelial cells in physiology and in the pathophysiology of vascular disorders. Blood, 91:3527-61.

Collier A, Rumley A, Rumley AG, et al. 1992. Free radical activity and hemostatic factors in NIDDM patients with and without microalbuminuria. Diabetes, 41:909-13.

Consensus Development Conference on Insulin Resistance. American Diabetes Association. 1998. Diabetes Care, 21:310-4.

Cruickshank K, Riste L, Anderson SG, et al. 2002. Aortic pulse-wave velocity and its relationship to mortality in diabetes and glucose intolerance: an integrated index of vascular function? Circulation, 106:2085-90.

Deanfield J, Donald A, Ferri C, et al. 2005. Endothelial function and dysfunction. Part I: Methodological issues for assessment in the different vascular beds: a statement by the Working Group on Endothelin and Endothelial Factors of the European Society of Hypertension. J Hypertens, 23:7-17.

Ding H, Triggle CR. 2005. Endothelial cell dysfunction and the vascular complications associated with type 2 diabetes: assessing the health of the endothelium. Vasc Health Risk Manag, 1:55-71.

Erem C, Hacihasanoglu A, Celik S, et al. 2005. Coagulation and fibrinolysis parameters in type 2 diabetic patients with and without diabetic vascular complications. Med Princ Pract, 14:22-30.

European Society of Hypertension-European Society of Cardiology guidelines for the management of arterial hypertension. 2003. J Hypertens, 21:1011-53.

Feletou M, Vanhoutte PM. 2006. Endothelial dysfunction: a multifaceted disorder. Am J Physiol Heart Circ Physiol, 291:H985-H1002.

Gerstein HC, Mann JF, Yi Q, et al. 2001. Albuminuria and risk of cardiovascular events, death, and heart failure in diabetic and nondiabetic individuals. JAMA, 286:421-6.

Glanz SA. 1992. Primer of biostatistics. 3rd ed. New York: McGraw-Hill. pp. 350-2.

Golay S, Haeberli C, Delachaux A, et al. 2004. Local heating of human skin causes hyperemia without mediation by muscarinic cholinergic receptors or prostanoids. J Appl Physiol, 97:1781-6.

Henry RM, Kostense PJ, Spijkerman AM, et al. 2003. Arterial stiffness increases with deteriorating glucose tolerance status: the Hoorn Study. Circulation, 107:2089-95.

Hogikyan RV, Galecki AT, Pitt B, et al. 1998. Specific impairment of endothelium-dependent vasodilation in subjects with type 2 diabetes independent of obesity. J Clin Endocrinol Metab, 83:1946-52.

Jaap AJ, Hammersley MS, Shore AC, et al. 1994. Reduced microvascular hyperaemia in subjects at risk of developing type 2 (non-insulin-dependent) diabetes mellitus. Diabetologica, 37:214-6.

Jaap AJ, Shore AC, Tooke JE. 1997. Relationship of insulin resistance to microvascular dysfunction in subjects with fasting hyperglycaemia. Diabetologia, 40:238-43.

Jermendy G, Farkas K, Nadas J, et al. 2001. Practical aspects of measuring microalbuminuria in diabetic patients. Diab Nutr Metab, 14:195-200.

Kario K, Matsuo T, Kobayashi H, et al. 1995. Activation of tissue factor-induced coagulation and endothelial cell dysfunction in non-insulin-dependent diabetic patients with microalbuminuria. Arterioscler Thromb Vasc Biol, 15:1114-20.

Kathiresan S, Gona P, Larson MG, et al. 2006. Cross-sectional relations of multiple biomarkers from distinct biological pathways to brachial artery endothelial function. Circulation, 113:938-45.

Kato H. 2002. Regulation of functions of vascular wall cells by tissue factor pathway inhibitor: basic and clinical aspects. Arteriosclerosis Thromb Vasc Biol, 22:539-48. 
Kellogg DL, Jr, Liu Y, Kosiba IF, et al. 1999. Role of nitric oxide in the vascular effects of local warming of the skin in humans. J Appl Physiol, $86: 1185-90$.

Kim JA, Montagnani M, Koh KK, et al. 2006. Reciprocal relationships between insulin resistance and endothelial dysfunction: molecular and pathophysiological mechanisms. Circulation, 113:1888-904.

Kubli S, Waeber B, Dalle-Ave A, et al. 2000. Reproducibility of laser Doppler imaging of skin blood flow as a tool to assess endothelial function. J Cardiovasc Pharmacol, 6:640-8.

Laasko M, Lehto S. 1997. Epidemiology of macrovascular disease in diatetes. Diab Rev, 5:294-315.

Laurent S, Cockcroft J, Van Bortel L, et al. 2006. Expert consensus document on arterial stiffness: methodological issues and clinical applications. Eur Heart J, 27:2588-605.

Leurs PB, Stolk RP, Hamulyak K, et al. 2002. Tissue factor pathway inhibitor and other endothelium-dependent hemostatic factors in elderly individuals with normal or impaired glucose tolerance and type 2 diabetes. Diabetes Care, 25:1340-5.

Libby P, Simon DI. 2001. Inflammation and thrombosis: the clot thickens. Circulation, 103:1718-20.

Lim SC, Caballero AE, Smakowski P, et al. 1999. Soluble intercellular adhesion molecule, vascular cell adhesion molecule, and impaired microvascular reactivity are early markers of vasculopathy in type 2 diabetic individuals without microalbuminuria. Diabetes Care, 22:1865-70.

McGill JB, Schneider DJ, Arfken CL, et al. 1994. Factors responsible for impaired fibrinolysis in obese subjects and NIDDM patients. Diabetes, 43:104-9.

Morange PE, Renucci JF, Charles MA, et al. 2001. Plasma levels of free and total TFPI, relationship with cardiovascular risk factors and endothelial cell markers. Thromb Haemost, 85:999-1003.

Morange PE, Simon C, Alessi MC, et al. 2004. Endothelial cell markers and the risk of coronary heart disease. Circulation, 109:1343-8.

Morris SJ, Shore AC, Tooke JE. 1995. Responses of the skin microcirculation to acetylcholine and sodium nitroprusside in patients with NIDDM. Diabetologia, 38:1337-44.

Murray CJ, Lopez AD. 1996. Evidence-based health policy - lessons from the Global Burden of Disease Study. Science, 274:740-43.

Naghavi M, Libby P, Falk E, et al.2003.. From vulnerable plaque to vulnerable patient: a call for new definitions and risk assessment strategies: Part II. Circulation, 108:1772-8.

Natali A, Toschi E, Baldeweg S, et al. 2006. Clustering of insulin resistance with vascular dysfunction and low-grade inflammation in type 2 diabetes. Diabetes, 55:1133-40.

Nathan DM. 1993. Long-term complications of diabetes mellitus. N Engl J Med, 328:1676-85.

Pinkney JH, Stehouwer CD, Coppack SW, et al. 1997. Endothelial dysfunction: cause of the insulin resistance syndrome. Diabetes, 46 (Suppl 2):S9-S13.
Pyorala M, Miettinen H, Halonen P, et al. 2000. Insulin resistance syndrome predicts the risk of coronary heart disease and stroke in healthy middleaged men: the 22-year follow-up results of the Helsinki Policemen Study. Arterioscler Thromb Vasc Biol, 20:538-44.

Reaven GM, Lithell H, Landsberg L. 1996. Hypertension and associated metabolic abnormalities - the role of insulin resistance and the sympathoadrenal system. N Engl J Med, 334:374-81.

Rigla M, Wagner AM, Borrell M, et al. 2006. Postprandial thrombin activatable fibrinolysis inhibitor and markers of endothelial dysfunction in type 2 diabetic patients. Metab, 55:1437-42.

Ross R. 1999. Atherosclerosis - an inflammatory disease. N Engl J Med, 340:115-26.

Stansberry KB, Peppard HR, Babyak LM, et al. 1999. Primary nociceptive afferents mediate the blood flow dysfunction in non-glabrous (hairy) skin of type 2 diabetes: a new model for the pathogenesis of microvascular dysfunction. Diabetes Care, 22:1549-54.

Vehkavaara S, Seppala-Lindroos A, Westerbacka J, et al. 1999. In vivo endothelial dysfunction characterizes patients with impaired fasting glucose. Diabetes Care, 22:2055-60.

Verma S, Anderson TJ. 2002. Fundamentals of endothelial function for the clinical cardiologist. Circulation, 105:546-9.

Verma S, Buchanan MR, Anderson TJ. 2003. Endothelial function testing as a biomarker of vascular disease. Circulation, 108:2054-9.

Vinik AI, Erbas T, Park TS, et al. 2001. Dermal neurovascular dysfunction in type 2 diabetes. Diabetes Care, 24:1468-75.

Waeber B, Feihl F, Ruilope L. 2001. Diabetes and hypertension. Blood Pressure, 10:311-21.

Waeber B, Feihl F. 2005. Oxidative stress: a pivotal link among cardiovascular risk factors? Curr Hypertens Rep, 7:229-30.

Wardell K, Naver HK, Nilsson GE, et al. 1993. The cutaneous vascular axon reflex in humans characterized by laser Doppler perfusion imaging. J Physiol, 460:185-99.

Wheatcroft SB, Williams IL, Shah AM, et al. 2003. Pathophysiological implications of insulin resistance on vascular endothelial function. Diab Med, 20:255-68.

Williams SB, Cusco JA, Roddy MA, et al. 1996. Impaired nitric oxide-mediated vasodilation in patients with non-insulin-dependent diabetes mellitus. J Am Coll Cardiol, 27:567-74.

Yano Y, Kitagawa N, Gabazza EC, et al. 2003. Increased plasma thrombin-activatable fibrinolysis inhibitor levels in normotensive type 2 diabetic patients with microalbuminuria. J Clin Endocrinol Metab, 88:736-41

Zenere BM, Arcaro G, Saggiani F, et al. 1995. Noninvasive detection of functional alterations of the arterial wall in IDDM patients with and without microalbuminuria. Diabetes Care, 18:975-82. 